\title{
Efficacy and safety of a vaginal medicinal product containing three strains of probiotic bacteria: a multicenter, randomized, double-blind, and placebo-controlled trial
}

\author{
This article was published in the following Dove Press journal: \\ Drug Design, Development and Therapy \\ 25 September 2015 \\ Number of times this article has been viewed
}

\author{
Anna Tomusiak' \\ Magdalena Strus' \\ Piotr B Heczko' \\ Paweł Adamski² \\ Grzegorz Stefański ${ }^{3}$ \\ Aleksandra Mikołajczyk- \\ Cichońska ${ }^{3}$ \\ Magdalena Suda-Szczurek ${ }^{3}$ \\ 'Department of Microbiology, \\ Jagiellonian University Medical \\ College, ${ }^{2}$ Institute of Nature \\ Conservation, Polish Academy \\ of Sciences, ${ }^{3}$ IBSS BIOMED SA, \\ Kraków, Poland
}

\begin{abstract}
Objective: The main objective of this study was to evaluate whether vaginal administration of probiotic Lactobacillus results in their colonization and persistence in the vagina and whether Lactobacillus colonization promotes normalization and maintenance of $\mathrm{pH}$ and Nugent score.

Patients and methods: The study was a multicenter, randomized, double-blind, and placebocontrolled trial. Altogether, 376 women were assessed for eligibility, and signed informed consent. One hundred and sixty eligible women with abnormal, also called intermediate, vaginal microflora, as indicated by a Nugent score of 4-6 and $\mathrm{pH}>4.5$ and zero or low Lactobacillus count, were randomized. Each participant was examined four times during the study. Women were randomly allocated to receive either the probiotic preparation inVag ${ }^{\circledR}$, or a placebo (one capsule for seven consecutive days vaginally). The product inVag includes the probiotic strains Lactobacillus fermentum 57A, Lactobacillus plantarum 57B, and Lactobacillus gasseri 57C. We took vaginal swabs during visits I, III, and IV to determine the presence and abundance of bacteria from the Lactobacillus genus, measure the $\mathrm{pH}$, and estimate the Nugent score. Drug safety evaluation was based on analysis of the types and occurrence of adverse events.

Results: Administration of inVag contributed to a significant decrease (between visits) in both vaginal $\mathrm{pH}(P<0.05)$ and Nugent score $(P<0.05)$, and a significant increase in the abundance of Lactobacillus between visit I and visits III and IV $(P<0.05)$. Molecular typing revealed the presence of Lactobacillus strains originating from inVag in $82 \%$ of women taking the drug at visit III, and $47.5 \%$ at visit IV. There was no serious adverse event related to inVag administration during the study.
\end{abstract}

Conclusion: The probiotic inVag is safe for administration to sustainably restore the healthy vaginal microbiota, as demonstrated by predominance of the Lactobacillus bacteria in vaginal microbiota.

Keywords: probiotics, Lactobacillus, bacterial vaginosis, aerobic vaginitis

\section{Introduction}

Vaginal microbiota is dominated by Gram-positive Lactobacillus bacteria, which maintain the acidic $\mathrm{pH}$ in the vagina and protect it from pathogen invasion by the production of organic acid, bacteriocins, and hydrogen peroxide. ${ }^{1}$ Other bacterial species such as Gardnerella vaginalis, Peptostreptococcus spp., Prevotella spp., Escherichia coli, Streptococcus agalactiae, and Enterococcus faecalis are present in limited quantities in a healthy vagina, but in certain conditions, their populations may increase significantly, which can cause diseases such as bacterial vaginosis (BV) or aerobic vaginitis $(\mathrm{AV}){ }^{2}{ }^{2}$ These diseases are diagnosed using both clinical and microbiological criteria.
Correspondence: Magdalena Strus Department of Microbiology, Jagiellonian University Medical College, Kraków ul. Czysta 18, 3I-I2I Kraków, Poland

$\mathrm{Tel}+48 \mathrm{I} 26332567$

Fax +48124233924

Email mbstrus@cyf-kr.edu.pl 
Clinical criteria include, among other signs and symptoms, elevated vaginal $\mathrm{pH}(>4.5),{ }^{3}$ while the microbiological criterion involves the microscopic assessment of vaginal microbiota according to the Nugent score. A score of 4-6 indicates an abnormal condition, also called intermediate vaginal microflora, and a score of 7-10 suggests the presence of BV. ${ }^{3,4}$ Abnormal vaginal microflora, although asymptomatic, often leads to vaginal infections when left untreated. ${ }^{4,5}$

Treating BV and AV with antibiotics and chemotherapeutics is often ineffective and results in relapses; however, administration of viable probiotic strains of Lactobacillus can promote success of these therapies, or they may be used as a prophylactic. ${ }^{6-8}$ As stated by Mastromarino et $\mathrm{al}^{9}$ the majority of clinical trials yielding positive results have been performed using probiotic preparations containing high doses of lactobacilli, suggesting that, beside strain characteristics, the amount of exogenously applied lactobacilli could have a role in the effectiveness of the product. However, substantial heterogeneity in products, trial methodologies, and outcome measures do not provide sufficient evidence for or against recommending probiotics for the treatment of BV. Therefore, each new probiotic product designed to improve vaginal health should be evaluated separately in controlled clinical studies.

Recently, Hemalatha et $\mathrm{al}^{10}$ published their study on vaginal tablets containing a probiotic mixture in which also women with symptomatic BV and with intermediate flora were involved. However, there is no published clinical trial specifically addressed to study the effects of probiotics on nonclinical parameters of the vaginal health in women with altered microbiota.

\section{Objective}

We aimed to evaluate whether vaginal administration of probiotic bacteria contained in a novel medicinal product consisting of three well-characterized Lactobacillus strains to women with abnormal microflora results in colonization and persistence of Lactobacillus in the vagina and a restoration of normal $\mathrm{pH}$ and reduction in the Nugent score as sensitive parameters of the vaginal healthy status. Further, we evaluated drug safety by measuring the severity and frequency of adverse events following application of the probiotic preparation inVag ${ }^{\circledR}$.

\section{Patients and methods Study design}

This multicenter, randomized, double-blind, placebocontrolled, parallel-group study with two randomization arms (1:1) was conducted in accordance with the original protocol PB-DM/SBR-L3 - 01/05. The trial received ethical approval on June 23, 2005, from the Independent Ethics Committee of Jagiellonian University (relevant for the study coordinator) and Regulatory Authority approval on September 21, 2005. This study has been entered into the Central Register of Clinical Trials under No 284/UR/ CEBK/09/05 dated September 27, 2005.

The study took place between February 2006 and June 2008 in nine study centers, the Gynecology Clinic University Hospital, and eight private outpatient gynecology practices (Krakow, Poland).

\section{Participants and data collection}

The trial involved 376 women (Figure 1); the first participant was enrolled in the trial on February 21, 2006, and the last participant completed the trial on June 13, 2008. The 160 eligible participants consisted of 18-40-year-old women of European descent who needed to rebalance and/or restore their vaginal bacterial community, which was dysbiotic, ie, lacking of the Lactobacillus predominance, due to factors including antibiotic therapy, radiation therapy, chemotherapy, and hormonal therapy. Women who were qualified to the clinical trial did not manifest any clinical signs of acute inflammation of the genital tract, but only needed to rebalance and/or restore their vaginal bacterial microflora. The participants had suitable personal hygiene and provided written informed consent. Detailed inclusion and exclusion criteria can be found in Table 1 .

The trial included four visits. The first visit included screening and enrollment; in the second visit the participants were randomized; and the third and fourth visits were follow-ups. Including the follow-up visits, the duration of participation in the trial was approximately 19 days. We allowed extension of the participation period by 7 days to account for interruptions in inVag administration due to menstruation.

A clinical investigator examined all participants and recorded medical histories and clinical symptoms. High vaginal swabs for wet preparations and Gram-stain smears were collected at visits I, III, and IV. Samples were sent to the central laboratory (Department of Microbiology, Jagiellonian University Medical College, Krakow, Poland) for quantitative and qualitative analysis of microbiological cultures. These analyses included determination of the presence and abundance of Lactobacillus, bacterial and yeast pathogens, as well as vaginal $\mathrm{pH}$ and the Nugent score. The results from visits III and IV were compared with those from the first visit. Any adverse events following inVag 


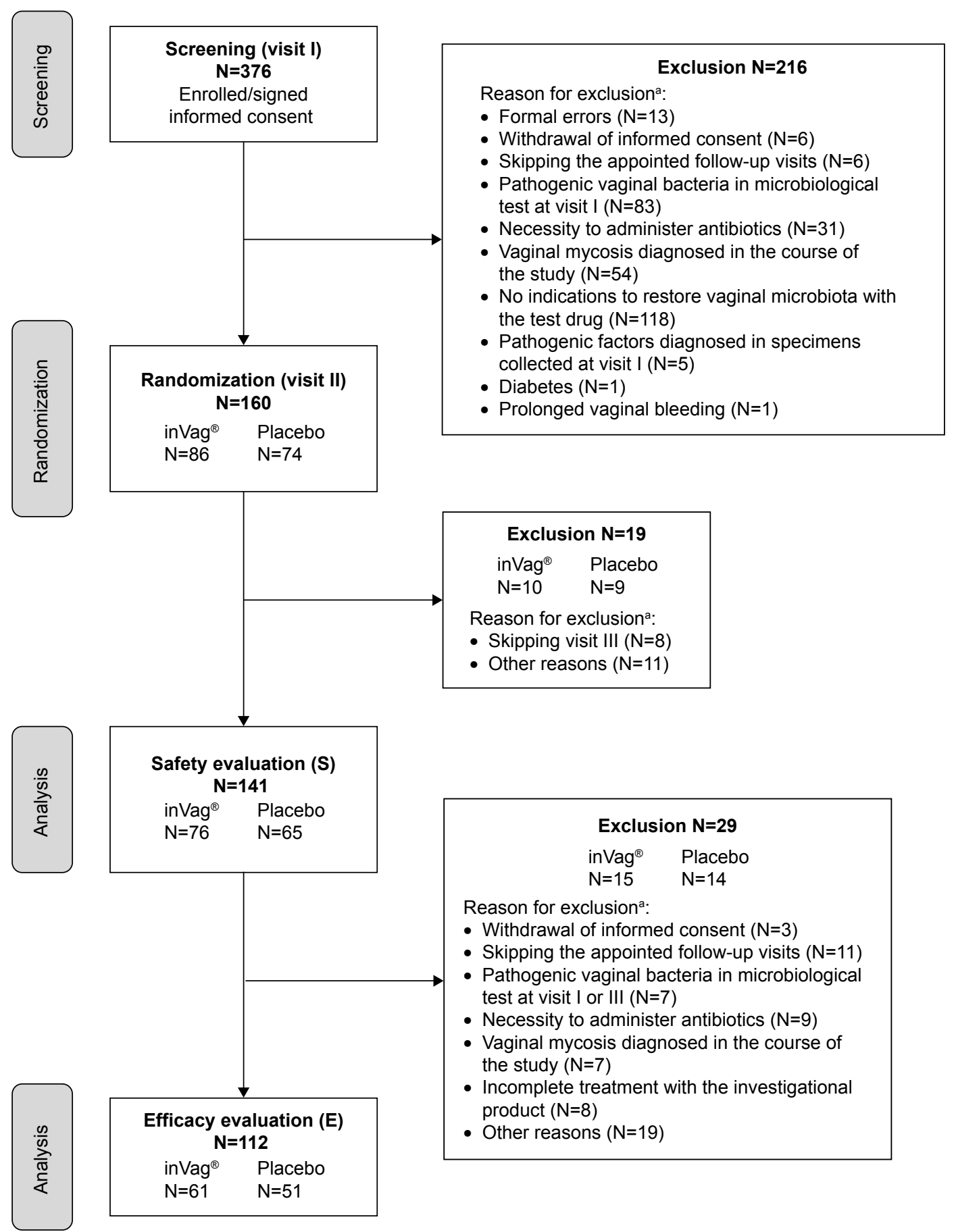

Figure I Flowchart of the clinical study.

Note: as per protocol, a participant could be withdrawn from the clinical trial for more than one reason.

administration were documented at visits III and IV based on medical history, physical examination, and analysis of "patient diary" entries.

The final inclusion criterion was based on the microbiological tests performed in the first visit. These results were confirmed by the second visit, and if the patient had a Nugent score of 4-6, a low number or lack of Lactobacillus, and/or a high vaginal $\mathrm{pH}$, they were enrolled as participants, randomized, and allocated either inVag or the placebo according to a computer-generated sequence. The presence of the bacterial or fungal etiological agent of vaginal infection, whose number, based on viable count method, on the first visit was $\geq 1.0 \times 10^{5}$ colony forming units $(\mathrm{CFU}) / \mathrm{mL}$ concurrent with the occurrence of clinical symptoms of 
Table I Patient exclusion and inclusion criteria

\begin{tabular}{|c|c|}
\hline Inclusion criteria & Exclusion criteria \\
\hline Indications to rebalance and/or restore natural vaginal microbiota, due to antibiotic & Patients $<18$ years and $>45$ years of age \\
\hline therapy, radiation therapy, chemotherapy, hormonal therapy, etc & Hypersensitivity to any of the ingredients contained in the \\
\hline Women aged $\geq 18$ years and $\leq 45$ years & probiotic or placebo \\
\hline Women of European descent & Vaginal bleeding of unknown etiology \\
\hline Suitable personal hygiene routines & Positive result of a pregnancy test \\
\hline \multirow[t]{9}{*}{ Suitable intellectual level that ensures appropriate cooperation } & Breastfeeding \\
\hline & Active genitourinary tract infection that requires antibiotic \\
\hline & treatment against bacteria, viruses, fungi, or protozoa \\
\hline & Innate (congenital) and acquired immunodeficiencies \\
\hline & Diabetes \\
\hline & Mental illness \\
\hline & Status after bilateral adnexa removal \\
\hline & Advanced cancer (terminal cancer) \\
\hline & Participation in another clinical study \\
\hline
\end{tabular}

vaginosis or vaginitis was the basis for exclusion from the study. Eligible women were given one package that contained seven capsules. Starting from the day of the second visit, participants were to vaginally administer one capsule of probiotic or placebo daily before going to bed for seven consecutive days.

\section{Randomization, allocation, and blinding}

Each study center received randomization datasets and a set of packages containing the probiotic or placebo, labeled with numerical codes (from 001 to 280) assigned to one of the two treatment groups. Each participant was assigned an ID number composed of a two-digit study center number and a three-digit screening number. After randomization, a threedigit randomization number (from 001 to 280) was added to the participant's ID to identify the randomization dataset. The participants, investigators, clinic and central laboratory staff, and study monitors were blinded to the treatment group.

The tested product was a vaginal medicinal product in gelatin capsules (inVag) or a placebo. The manufacturer and sponsor (IBSS Biomed SA, Krakow, Poland) of the trial provided both the active product and placebo. The active product contained a mixture of three viable bacterial strains present at numbers $>10^{9} \mathrm{CFU}: 25 \%$ Lactobacillus fermentum 57A, 25\% Lactobacillus plantarum 57B, 50\% Lactobacillus gasseri 57C, and excipients. The placebo was identical in appearance but contained only excipients with no bacteria. Strains included in inVag are the lactic acid bacteria L. fermentum 57A, L. plantarum 57B, and L. gasseri $57 \mathrm{C}$, which were isolated from a vaginal swab taken from a healthy woman aged 27 years not using antibiotics for the last 3 months. The strains possessed high coaggregating abilities and naturally occurred as a triad strains complex.
Their species designation was confirmed by polymerse chain reaction for $16 \mathrm{~S}$ RNA using species-specific primers, and they were identified using both pulse-field gel electrophoresis (L. fermentum 57A and L. gasseri 57C) and multilocus sequence typing (L. plantarum 57B) methods to distinguish them from other strains in materials taken during clinical study. They have been deposited in the international collection of microorganisms and covered with a patent. They had been selected for commercial use on the basis of their high adherence ability to the A431 vaginal cell line (and also to Caco-2 enterocytes), ability of selected vaginal pathogen adhesion reduction already adhered to these lines, and broad antagonistic properties exerted against $G$. vaginalis, S. agalactiae, $P$. bivia, $S$. aureus, E. faecalis, C. difficile, and uropathogenic E. coli. L. gasseri $57 \mathrm{C}$ produces hydrogen peroxide. All of them are resistant to metronidazole and ciprofloxacin. L. fermentum 57A and L. plantarum 57B are vancomycin-resistant, while $L$. gasseri $57 \mathrm{C}$ is sensitive to vancomycin. The strains carry no extrachromosomal DNA elements able to transmit resistance to antibiotics, and they are resistant to spermicides such as nonoxynol-9 (and additionally to gastric juice with pepsin pH 2.5 and to bile salts).

\section{Microbiology}

All tests were performed in a central laboratory. The material from the clinical samples was cultured in relevant growth media: MRS Agar (Oxoid) for Lactobacillus, Columbia Blood Agar (CBA, Difco) for aerobic bacteria, MacConkey Agar (Biocorp) for Gram-negative rods, Enterococcosel Agar (BBL) for E. faecalis, Schaedler Agar (Difco) with vitamin $\mathrm{K}$ and 5\% sheep blood for anaerobic bacteria, and CBA with a suitable supplement of human blood for $G$. vaginalis. For Candida fungi we used Sabouraud Agar (Biocorp). 
After cultivation in appropriate conditions, the pure cultures were obtained and phenotypic characterization of the obtained isolates was made. We used the following API (bioMérieux) tests for species identification: API STREP (for Streptococcus and Enterococcus), API STAPH (for Staphylococcus), API 20E (for Enterobacteriaceae), API 20A (for anaerobic bacteria), and API 50CH (for Lactobacillus). The results were analyzed with API LAB software for classification of the test bacteria. The numbers of Lactobacillus and pathogens were measured by a standard viable count method on MRS Agar or other suitable agar as indicated earlier. Vaginal $\mathrm{pH}$ was determined using $\mathrm{pH}$ indicator strips by Merck (Germany) with a measuring range 4.0-7.0. Vaginal microflora was evaluated using a Gram-stained smear and the 10-point Nugent score. ${ }^{4}$ Additional analyses using polymerse chain reaction ${ }^{11}$ for molecular species identification and pulse-field gel electrophoresis or multilocus sequence typing $^{5,12}$ for intraspecific molecular typing were performed after the completion of the study to confirm colonization by the Lactobacillus strains contained in the active product.

\section{Safety evaluation}

Our safety evaluation consisted of an assessment of the incidence and type of adverse events and serious adverse events after application of the tested product. Specifically, we analyzed the occurrence or intensification of local symptoms (pruritus, pain, vaginal discharge, labia swelling), allergic reaction, fever, hypogastric pain, pain during urination, breathing difficulties, and other unexpected adverse events. Data on adverse events were collected throughout the duration of patient participation in the study.

\section{Sample size}

To calculate sample size, we assumed a test power of $\beta>0.80$, a critical significance level $P=0.05$, and similar differences between treatment groups (active vs placebo) achieved in the preliminary study. This resulted in a suggested sample size equal to or greater than 56 participants. We assumed that $20 \%$ of participants might fail to complete the study per protocol, thus we recruited 68 women for each treatment group.

\section{Statistical analysis}

The data were explained using descriptive statistical methods appropriate for the type of variables analyzed. For nominal variables, we determined the ratios of specific values. For continuous variables, we calculated the arithmetic mean (with standard error) and the median to define the central tendencies. We also included data on variation such as standard deviation, minimum and maximum values, and quartile limits. Due to the non-normal data distribution, for bacterial abundance measured in CFU/mL, a decimal-logarithmic data transformation was done. Inductive statistical methods were used to compare treatment groups. Because the distribution of quantitative variables significantly deviated from the normal distribution, even when data transformations were excluded, a nonparametric Wilcoxon rank-sum test was used. To avoid possible artifacts resulting from individual differences between patients, matched-pairs tests were used in comparisons between visits. For data analysis concerning the Nugent score, which is an ordinal variable, comparisons were made using a median test. For qualitative variables, Pearson's $\chi^{2}$ (chi-square) tests or the less restrictive alternative $G^{2}$ (likelihood ratio) tests were applied. If specific data were missing, pairwise deletion was used during the course of analysis.

\section{Results}

\section{Baseline characteristics}

Out of 376 women enrolled in the study, 160 were randomized, 112 completed the full study cycle, and 48 (30\%) were excluded for various reasons (Figure 1). Efficacy evaluation was done for 112 women (61 received the active product and 51 received placebo) who completed the study as per protocol, ie, they completed all four visits and were not excluded (Table 2). Safety analysis was done for 141 women ( 76 received the active product and 65 received placebo) who were enrolled, randomized, and used at least one capsule of the product (Table 2 ).

Analysis of the data collected from patients during the first visit revealed that participant populations for efficacy and safety evaluations were not different in terms of demographic, clinical, or epidemiological parameters (Table 3).

\section{Efficacy outcomes}

The efficacy analysis based on 112 participants was based on vaginal $\mathrm{pH}$, microbiological Nugent score, and degree and persistence of vaginal colonization by at least one of Lactobacillus strains from the active product. Statistical analysis

Table 2 Populations of patients evaluated for safety and efficacy of inVag ${ }^{\circledR}$ treatment

\begin{tabular}{llll}
\hline & $\begin{array}{l}\text { Total number } \\
\text { of patients }\end{array}$ & $\begin{array}{l}\text { Patients } \\
\text { using inVag }\end{array}$ & $\begin{array}{l}\text { Patients } \\
\text { using placebo }\end{array}$ \\
\hline Patients (randomized) & $160(100 \%)$ & $86(100 \%)$ & $74(100 \%)$ \\
Safety evaluation (S) & $141(88 \%)$ & $76(88 \%)$ & $65(88 \%)$ \\
Efficacy evaluation (E) & $112(70 \%)$ & $61(71 \%)$ & $51(69 \%)$ \\
\hline
\end{tabular}


Table 3 Baseline characteristics of participants

\begin{tabular}{|c|c|c|c|}
\hline Characteristic & Placebo & inVag & $P$-value \\
\hline \multicolumn{4}{|l|}{ Average age of patients participating in the clinical study } \\
\hline Group Sa & 31.12 & 29.14 & 0.1121 \\
\hline Group $E^{\mathrm{b}}$ & 30.95 & 29.30 & 0.2468 \\
\hline \multicolumn{4}{|l|}{ Reason for visit I (enrollment to the study) } \\
\hline Follow-up after BV therapy (S) & 21 & 20 & 0.4348 \\
\hline Follow-up after BV therapy (E) & 16 & 16 & 0.5489 \\
\hline Follow-up after vaginal candidiasis treatment $(\mathrm{S})$ & 12 & 19 & 0.3501 \\
\hline Follow-up after vaginal candidiasis treatment $(\mathrm{E})$ & 7 & 16 & 0.1028 \\
\hline Follow-up after chemotherapy (S) & I & 1 & 0.9113 \\
\hline Follow-up after chemotherapy (E) & I & 1 & 0.8982 \\
\hline Follow-up after antibiotic treatment ${ }^{\mathrm{c}}(\mathrm{S})$ & 6 & 10 & 0.4636 \\
\hline Follow-up after antibiotic treatment ${ }^{c}(E)$ & 3 & 8 & 0.2003 \\
\hline Other $(S)$ & 34 & 45 & 0.4104 \\
\hline Other (E) & 27 & 36 & 0.5186 \\
\hline \multicolumn{4}{|l|}{ Number of BV or vaginal candidiasis episodes } \\
\hline One $(S)$ & 8 & II & $0.3486(S)$ \\
\hline One (E) & 6 & 8 & $0.2380(\mathrm{E})$ \\
\hline Two $(S)$ & 3 & 6 & \\
\hline Two $(E)$ & 2 & 6 & \\
\hline Three and more $(\mathrm{S})$ & 18 & 12 & \\
\hline Three and more $(\mathrm{E})$ & 14 & 10 & \\
\hline \multicolumn{4}{|c|}{ Use of an antibiotic/chemotherapeutic before enrollment to the clinical study } \\
\hline Oral & 14 & 17 & 0.9307 \\
\hline Vaginal & 15 & 17 & 0.2682 \\
\hline Intramuscular & 0 & 1 & 0.2738 \\
\hline Intravenous & I & 0 & 0.2009 \\
\hline \multicolumn{4}{|c|}{ Deviations from the norm observed by investigator at visit I during gynecological examination } \\
\hline Deviation from the norm (S) & 5 & 10 & 0.2941 \\
\hline Deviation from the norm $(E)$ & 3 & 9 & 0.1306 \\
\hline Vaginal discharge $(\mathrm{S})$ & 3 & 1 & 0.2394 \\
\hline Vaginal discharge (E) & 2 & I & 0.4563 \\
\hline Excessive secretion (S) & I & 2 & 0.6539 \\
\hline Excessive secretion $(\mathrm{E})$ & I & 2 & 0.6671 \\
\hline Erythema (S) & 0 & 1 & $0.265 I$ \\
\hline Erythema $(E)$ & 0 & 1 & 0.2688 \\
\hline Erosions of the epithelium (S) & I & I & 0.9113 \\
\hline Erosions of the epithelium (E) & 0 & 1 & 0.2688 \\
\hline Labia swelling $(\mathrm{S})$ & 0 & 1 & 0.2651 \\
\hline Labia swelling (E) & 0 & I & 0.2688 \\
\hline Other $(S)$ & I & 5 & 0.1394 \\
\hline Other $(E)$ & I & 4 & 0.2408 \\
\hline \multicolumn{4}{|l|}{ Other data in the medical history at visit I } \\
\hline Sexual activity & 44 & 51 & 0.6951 \\
\hline Use of condoms as a contraceptive method & 7 & 16 & 0.0793 \\
\hline Use of vaginal douching & 2 & 2 & 0.8554 \\
\hline Use of intimate hygiene products & 24 & 32 & 0.5692 \\
\hline History of pregnancy & 19 & 22 & 0.8965 \\
\hline History of undefined sexually transmitted diseases & 3 & 3 & 0.8180 \\
\hline History of Chlamydia trachomatis infection & 2 & 1 & 0.8270 \\
\hline Smoking & 5 & 14 & 0.0649 \\
\hline \multicolumn{4}{|l|}{ Concomitant therapy } \\
\hline Concomitant therapy (S) & 50 & 59 & 0.9202 \\
\hline Concomitant therapy $(\mathrm{E})$ & 37 & 46 & 0.7307 \\
\hline Hormone therapy ${ }^{d}(S)$ & 12 & 12 & 0.6739 \\
\hline Hormone therapy ${ }^{d}(E)$ & 10 & 10 & 0.6587 \\
\hline Contraception (S) & 21 & 22 & 0.6657 \\
\hline Contraception (E) & 16 & 17 & 0.6854 \\
\hline Menstrual cycle disorders (S) & 6 & 11 & 0.3575 \\
\hline Menstrual cycle disorders (E) & 5 & 9 & 0.4529 \\
\hline
\end{tabular}

Notes: aSafety evaluation group; 'bfficacy evaluation group; 'for reason other than BV and/or mycosis; 'excluding contraception. Abbreviation: BV, bacterial vaginosis. 
of the data revealed the following four main results: First, the group of women that received the probiotic experienced a significant reduction of vaginal $\mathrm{pH}$ between visits I and III - from 5.03 to $4.71(P<0.0016)$ and between visits I and IV - from 5.03 to $4.66(P<0.0001)$. A gradual decrease in vaginal $\mathrm{pH}$ was also seen in the placebo group; however, the change over time was not significant (Figure 2). Second, administration of the probiotic preparation resulted in a significant decrease in Nugent score between visit I and visits III - from 2.12 to $1.25(P=0.0001)$ and IV - from 2.12 to $0.9(P<0.0001)$. Additionally, the Nugent score decreased significantly between visits III and IV from 1.25 to 0.9 ( $P=0.0238$ ), which occurred approximately 14 days after cessation of inVag treatment. This suggests that a 7-day treatment cycle with inVag results in significant improvement of the vaginal microflora. The Nugent score also decreased significantly between visit I and visits III $(P<0.0001)$ and IV $(P=0.0002)$, in women who received placebo, but this group did not show the continuous decrease between visits III and IV (Figure 3). Changes in the vaginal microflora in women who used the probiotic preparation (according to Nugent score) are shown in Figure 4. Third, women who used the active product had a significant increase of the abundance of L. plantarum and L. fermentum in their vaginal microbiota. These species increased approximately 1,000 times over the 7 days (on average) after completion of the treatment (visit III), and then they slowly declined over the subsequent 8 days until visit IV. In patients who received the placebo, the abundance of $L$. plantarum and $L$. fermentum increased much more slowly than in patients who received the probiotic product. In this group, numbers of these strains only increased by $\sim 10$ times by the fourth visit.
The change in abundance of L. acidophilus and L. gasseri was similar in both treatment groups (Figure 5). Finally, the degree and sustainability of vaginal colonization by at least one Lactobacillus strain from the active product, based on molecular typing tests, confirmed colonization of the vaginal epithelium by L. fermentum 57A, L. plantarum 57B, and L. gasseri $57 \mathrm{C}$ in $82 \%$ of women who received the probiotic on visit III and $47.5 \%$ on visit IV.

\section{Safety outcomes}

Safety analysis included 141 participants. Out of the 141 women, 133 completed the whole treatment, that is, used seven capsules of the probiotic or placebo. The rate of occurrence of adverse events was unrelated to assignment to either of the treatment groups (probiotic or placebo), as the number of adverse events in each group was similar. In the probiotic group, 79 women reported adverse events, and in the placebo group 67 women reported adverse events. A total of 146 adverse events were reported in both treatment groups, the most common being genitourinary tract events $(60 \%$ of all reported adverse events); 88 adverse events of this type were reported in total.

A total of 49 genitourinary tract symptoms were observed in participants from the probiotic group. The most common symptoms reported by these women included vaginal discharge (16.46\% of all symptoms observed in probiotic group), pruritus (12.66\%), and hypogastric pain (7.59\%).

A total of 67 adverse events were reported by 42 among 65 participants receiving placebo. There were 39 cases of genitourinary system symptoms reported, dominated by vaginal discharge ( $19.40 \%$ of all symptoms in placebo group), pruritus (11.94\%), and burning sensation (10.45\%).

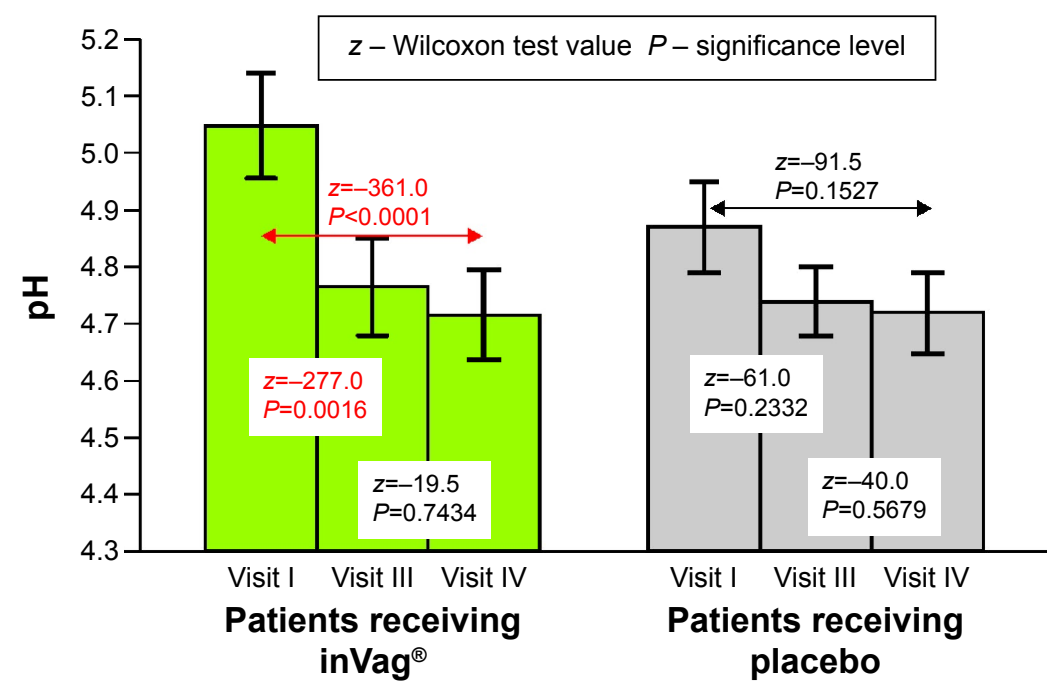

Figure 2 Changes in vaginal $\mathrm{pH}$ in patients receiving in $\mathrm{Vag}^{\circledR}$ or placebo at subsequent visits. 


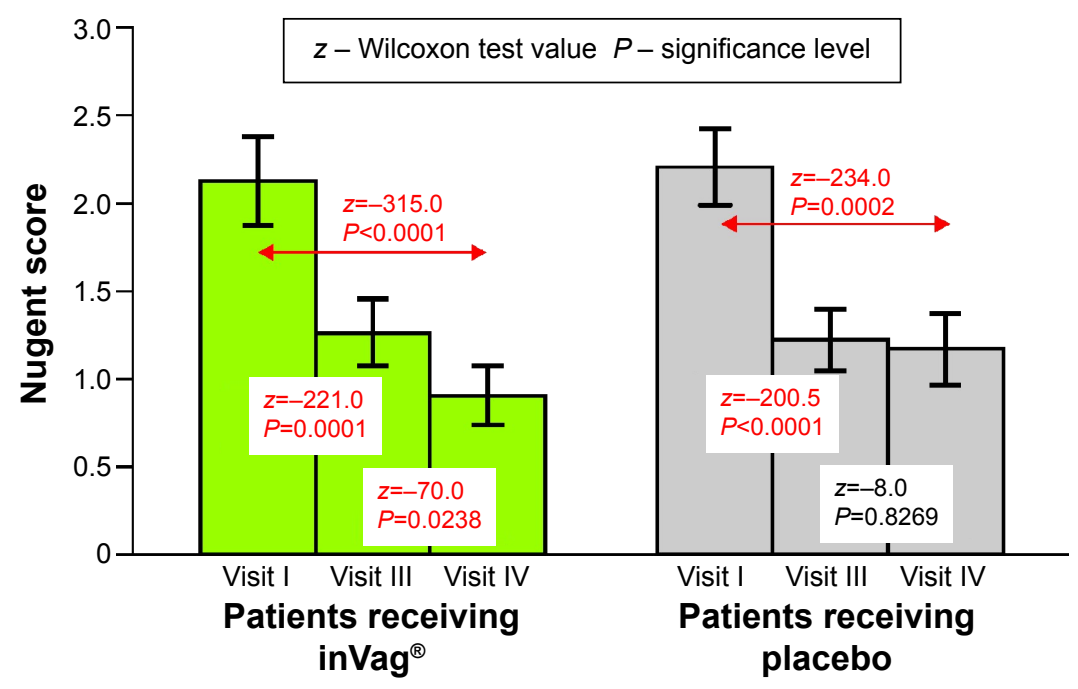

Figure 3 Changes in Nugent score in patients receiving inVag ${ }^{\circledR}$ or placebo at subsequent visits.

In both groups, a total of 71 adverse events were unrelated to the application of either probiotic or placebo, and 75 adverse events were related to the application, but in most of these cases these were classified as "mild severity" and "unlikely related". Analysis of the adverse events confirmed that no serious adverse event was related to the use of the probiotic.

\section{Discussion}

Safety and efficacy of probiotic bacterial preparations have to be confirmed by results of well-controlled clinical studies. The clinical trial described here was a double-blind, placebocontrolled clinical study, which demonstrated inVag therapy was significantly related to a gradual (visit-to-visit) decrease of vaginal $\mathrm{pH}$ and Nugent score. These positive changes likely resulted from colonization of the vaginal epithelium by the bacteria contained in the probiotic preparation. Other randomized, double-blind clinical trials also confirmed a quick and significant decrease of $\mathrm{pH}$ and Nugent score in women using vaginal gynecological probiotics as compared to the respective placebo group. ${ }^{10,13}$ These results indicate that one key advantage of vaginally administered probiotics is their quick local action, which is driven by the activity of probiotic bacteria that adhere to and colonize the vaginal epithelium.

The probiotic bacteria (L. fermentum 57A, L. plantarum 57B, and L. gasseri 57C) present in inVag were isolated from the healthy vaginal microbiota of a Polish woman. After the administration of inVag, we observed a fast and significant increase in the abundance of L. fermentum 57A, L. plantarum $57 \mathrm{~B}$, and L. gasseri $57 \mathrm{C}$ in the vaginal microbiota. These strains colonize vaginal environment rapidly
A

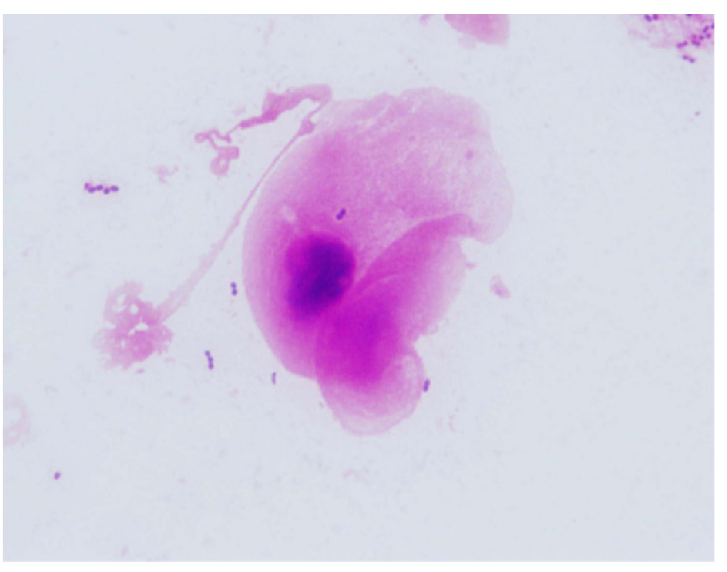

B

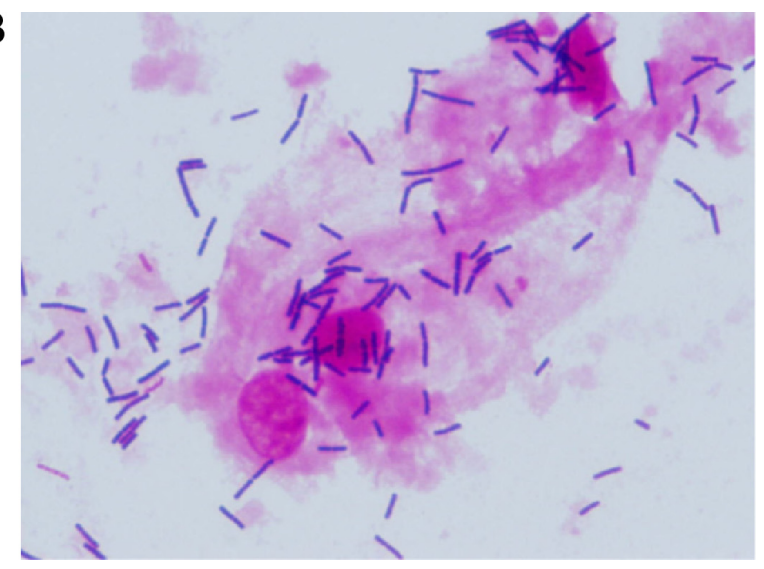

Figure 4 Representative images of the improvement in vaginal vaginosis in one woman after vaginal application of inVag.

Notes: Gram-stained preparations evaluated under I,000× magnification according to the I0-point Nugent scale. (A) A vaginal specimen obtained at visit I assessed at six points in Nugent scale. (B) A vaginal specimen obtained on the third visit assessed at zero points in Nugent scale. 


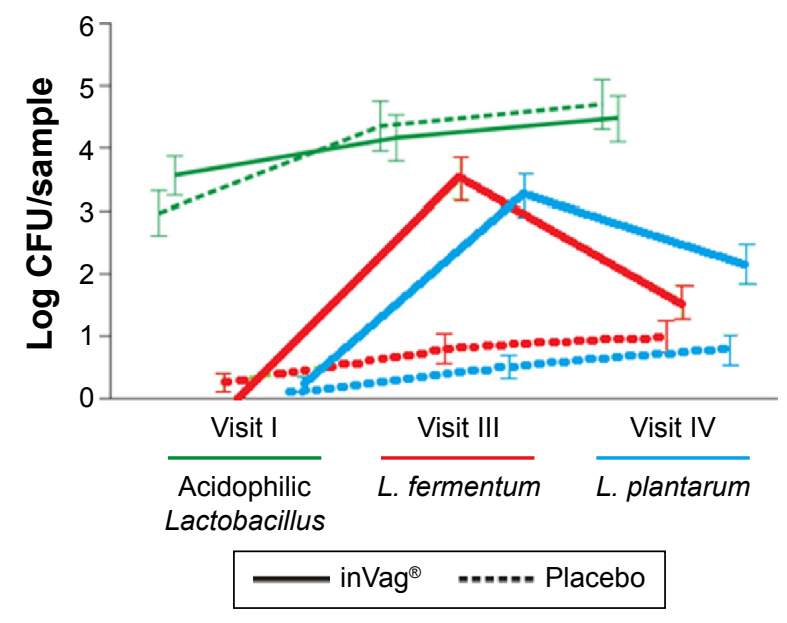

Figure 5 Comparison of changes in the abundance of L. fermentum, L. plantarum, and acidophilic Lactobacillus species in vaginal smears of patients receiving either inVag ${ }^{\circledR}$ or placebo.

Abbreviations: CFU, colony forming units; L. fermentum, Lactobacillus fermentum; L. plantarum, Lactobacillus plantarum.

and have very strong antagonistic properties toward potential vaginal bacterial pathogens. ${ }^{5}$ Moreover, due to their ability to decrease the $\mathrm{pH}$, these bacteria create favorable conditions for colonization by other Lactobacillus species that are regularly found in a healthy vaginal microbial community. Thus far, only two other clinical studies have reported the influence of probiotic strains with such well-characterized antagonistic and adhesive properties toward balancing vaginal bacterial microbiota. ${ }^{9}, 14$ In one, Anukam et al investigated an oral preparation containing L. rhamnosus GR-1 and L. reuteri RC-14 strains, and in the second, Mastromarino et al studied vaginal tablets containing $L$. brevis $\mathrm{CD} 2$, L. salivarius $\mathrm{FV} 2$, and L. plantarum FV9. ${ }^{9,14}$ Both studies demonstrated that administration of carefully selected Lactobacillus strains to women diagnosed with $\mathrm{BV}$ induces a faster restoration of healthy vaginal microbiota as compared to the control group and prevents remissions.

We used molecular typing to confirm the identity of Lactobacillus strains cultured from vaginal smears with those contained in inVag, which proved that the vaginal microbiota of $82 \%$ of women from the treatment group using inVag at visit III and $47.5 \%$ at visit IV were colonized with bacterial strains originating from inVag. Moreover, in $40 \%$ of patients, these bacteria were still present in vaginal smears after 15 days (on average) from the completion of treatment with inVag. These results demonstrate a stable colonization of vaginal probiotic bacteria in women treated with inVag.

This study was designed to check only the effects of the probiotic drug on normalization of the vaginal microbiota in women with altered/intermediate flora. Although initiation of the positive changes in the microbiota is important for this particular group of women, it is necessary to confirm whether InVag would be able to improve the clinical status in women with symptomatic BV and/or AV.

Probiotic preparations with viable lactic acid bacteria are generally regarded as safe because the bacteria are present in the healthy human vaginal microflora. ${ }^{15}$ Nevertheless, as with any biological preparation, adverse events of varying intensity may occur related to its use. These adverse events may include allergic reactions related to a hypersensitivity to components in the probiotic. ${ }^{16,17}$ Our safety evaluations of inVag treatment revealed that adverse events were unrelated to the use of the preparation or were reported as unlikely to be related and having mild severity. This analysis of adverse events justifies treating the probiotic as safe.

In summary, vaginally administered inVag is a safe and efficient treatment to restore and/or rebalance the vaginal microbiota with characteristic predominance of lactobacilli. Treatment with inVag also results in a reduction of the vaginal $\mathrm{pH}$ and Nugent score, which indicates restoration of natural balance of the vaginal microbiota. We postulate that the use of a gynecological probiotic is particularly recommended when quick restoration of vaginal microbiota is required, for example, after antibiotic treatment, chemotherapy, radiation therapy, or in supportive therapy of vaginal inflammatory conditions. The use of oral probiotics, on the other hand, which not only protect the vagina but also the gastrointestinal tract, should be considered for recurrent and secondary bacterial and fungal infections of the genitourinary system, in the peri- and postmenopausal period, and in women who frequently visit swimming pools, saunas, or Jacuzzis, and travel a lot. ${ }^{18}$ Indeed, the right choice of the gynecological probiotic is the first but crucial step to initiate rational approach to achieve healthy female genital microbiota in patients with abnormal microflora.

\section{Conclusion}

1) This study confirms the clinical and microbiological efficacy of the drug inVag in rebalancing and/or restoring the normal vaginal microbiota by providing probiotic bacteria that quickly and effectively colonize the vaginal epithelium.

2) The safety evaluation confirms that inVag is safe for use.

\section{Acknowledgments}

The authors wish to thank the participants and Professor A Basta (study coordinator), P Leszczyński (medical expert), and individual investigators M Gładysz, B Golański, R Jach, 
K Klimczyk, W Kolawa, A Krukierek, M Malinowska, and M Szlachcic. To conform to Good Clinical Practices, the entire course of the trial was monitored by an independent clinical research organization (CRO), which guaranteed protection of participants' rights and safety and completeness, reliability, and quality of the obtained data.

\section{Author contributions}

All authors contributed toward data analysis, drafting and critically revising the paper, and agree to be accountable for all aspects of the work.

\section{Disclosure}

GS, AM-C, and MS-S represent the sponsors, IBSS BIOMED S.A. and were responsible for the study design, documentation, and supervision of the whole clinical project including final manuscript. $\mathrm{PBH}, \mathrm{MS}$, and GS are coauthors of the patents covering the strains. No other conflict of interest exists beyond the contribution stated previously.

\section{References}

1. Dover SE, Aroutcheva AA, Faro S, Chikindas ML. Natural antimicrobials and their role in vaginal health: a short review. Int J Probiotics Prebiotics. 2008;3(4):219-230.

2. Donders GG, Vereecken A, Bosmans E, Dekeersmaecker A, Salembier G, Spitz B. Definition of a type of abnormal vaginal flora that is distinct from bacterial vaginosis: aerobic vaginitis. BJOG. 2002;109(1):34-43.

3. Drzewiecki A, Strus M, Heczko PB. Diagnostyka i leczenie tlenowego zapalenia pochwy i bakteryjnej waginozy [Diagnostics and treatment of aerobic vaginitis and bacterial vaginosis]. Med Prakt Ginek. 2005;6:1-5.

4. Nugent RP, Krohn MA, Hillier SL. Reliability of diagnosing bacterial vaginosis is improved by a standardized method of Gram stain interpretation. J Clin Microbiol. 1991;29:297-301.

5. Strus M, Chmielarczyk A, Kochan P, et al. Studies on the effects of probiotic Lactobacillus mixture given orally on vaginal and rectal colonization and on parameters of vaginal health in women with intermediate vaginal flora. Eur J Obstet Gynecol Reprod Biol. 2012;163(2):210-215.

6. Larsson PG, Stray-Pedersen B, Ryttig KR, Larsen S. Human lactobacilli as supplementation of clindamycin to patients with bacterial vaginosis reduce the recurrence rate; a 6-month, double-blind, randomized, placebo-controlled study. BMC Womens Health. 2008;8:3.
7. Ya W, Reifer C, Miller LE. Efficacy of vaginal probiotic capsules for recurrent bacterial vaginosis: a double-blind, randomized, placebocontrolled study. Am J Obstet Gynecol. 2010;203(2):.e1-.e6.

8. Delia A, Morgante G, Rago G, Musacchio MC, Petraglia F, De Leo V. Effectiveness of oral administration of Lactobacillus paracasei subsp. paracasei F19 in association with vaginal suppositories of Lactobacillus acidofilus in the treatment of vaginosis and in the prevention of recurrent vaginitis. Minerva Ginecol. 2006;58(3):227-231.

9. Mastromarino P, Macchia S, Meggiorini L, et al. Effectiveness of Lactobacillus-containing vaginal tablets in the treatment of symptomatic bacterial vaginosis. Clin Microbiol Infect. 2009;15(1):67-74.

10. Hemalatha R, Mastromarino P, Ramalaxmi BA, Balakrishna NV, Sesikeran B. Effectiveness of vaginal tablets containing lactobacilli versus $\mathrm{pH}$ tablets on vaginal health and inflammatory cytokines: a randomized, double-blind study. Eur J Clin Microbiol Infect Dis. 2012;31(11):3097-3105.

11. Walter J, Tannock GW, Tilsala-Timisjarvi A, et al. Detection and identification of gastrointestinal Lactobacillus species by using denaturing gradient gel electrophoresis and species-specific PCR primers. Appl Environ Microbiol. 2000;66(1):297-303.

12. Gosiewski T, Chmielarczyk A, Strus M, Brzychczy-Włoch M, Heczko PB. The application of genetics methods to differentiation of three Lactobacillus species of human origin. Ann Microbiol. 2012;62(4):1437-1445.

13. Petricevic L, Unger FM, Viernstein H, Kiss H. Randomized, doubleblind, placebo-controlled study of oral lactobacilli to improve the vaginal flora of postmenopausal women. Eur J Obstet Gynecol Reprod Biol. 2008;141(1):54-57.

14. Anukam K, Osazuwa E, Ahonkhai I, et al. Augmentation of antimicrobial metronidazole therapy of bacterial vaginosis with oral probiotic Lactobacillus rhamnosus GR-1 and Lactobacillus reuteri RC-14: randomized, double-blind, placebo controlled trial. Microbes Infect. 2006;8(6):1450-1454.

15. Borriello SP, Hammes WP, Holzapfel W, et al. Safety of probiotics that contain lactobacilli or bifidobacteria. Clin Infect Dis. 2003; 36(6):775-780.

16. Boyle RJ, Bath-Hextall FJ, Leonardi-Bee J, Murrell DF, Tang ML. Probotics for treating eczema. Cochrane Datebase Syst Rev. 2008;9:4.

17. Besselink MGH, van Santvoort HC, Buskens E, et al. Probiotic prophylaxis in predicted severe acute pancreatitis: a randomised, double-blind, placebo-controlled trial. Lancet. 2008;371:651-659.

18. Kotarski J, Dębski R, Drews K, et al. Opinia zespołu ekspertów Polskiego Towarzystwa Ginekologicznego dotycząca zastosowania preparatu prOVag w położnictwie i ginekologii [Opinion of the polish gynecological society's panel of experts on prOVag preparation use in obstetrics and gynecology]. Gin Dypl. 2008;2:106-108.
Drug Design, Development and Therapy

\section{Publish your work in this journal}

Drug Design, Development and Therapy is an international, peerreviewed open-access journal that spans the spectrum of drug design and development through to clinical applications. Clinical outcomes, patient safety, and programs for the development and effective, safe, and sustained use of medicines are a feature of the journal, which

\section{Dovepress}

has also been accepted for indexing on PubMed Central. The manuscript management system is completely online and includes a very quick and fair peer-review system, which is all easy to use. Visit http://www.dovepress.com/testimonials.php to read real quotes from published authors. 